\title{
Spatial Grain Effects of Urban Green Space Cover Maps on Assessing Habitat Fragmentation and Connectivity
}

\author{
Yue Lin ${ }^{1}$, Wenzhan An ${ }^{2}$, Muye Gan ${ }^{1,3, *}$, AmirReza Shahtahmassebi ${ }^{1}$, Ziran Ye ${ }^{4} \mathbb{D}$, Lingyan Huang ${ }^{5}$, \\ Congmou Zhu ${ }^{1}$, Lu Huang ${ }^{3}$, Jing Zhang ${ }^{1,6,7}$ and Ke Wang ${ }^{1,3}$
}

1 Institute of Applied Remote Sensing and Information Technology, College of Environment and Natural Resource, Zhejiang University, Hangzhou 310058, China; joyelin_2018@zju.edu.cn (Y.L.); amir511@zju.edu.cn (A.S.); congmouzhu1993@zju.edu.cn (C.Z.); zj1016@zju.edu.cn (J.Z.); kwang@zju.edu.cn (K.W.)

2 Zhejiang Institute of Territorial Spatial Planning, Hangzhou 310000, China; 21014137@zju.edu.cn

3 The Rural Development Academy, Zhejiang University, Hangzhou 310058, China; haoyubailu@zju.edu.cn

4 Institute of Digital Agriculture, Zhejiang Academy of Agricultural Sciences, Hangzhou 310021, China; yezr@zaas.ac.cn

5 School of Business, Zhejiang University City College, Hangzhou 310015, China; huangly@zucc.edu.cn

6 Key Laboratory of Urban Land Resources Monitoring and Simulation, Ministry of Natural Resources, Shenzhen 518000, China

7 Technology Innovation Center for Land Spatial Eco-Restoration in Metropolitan Area, Ministry of Natural Resources, Shanghai 200003, China

* Correspondence: ganmuye@zju.edu.cn

check for updates

Citation: Lin, Y.; An, W.; Gan, M.; Shahtahmassebi, A.; Ye, Z.; Huang, L.; Zhu, C.; Huang, L.; Zhang, J.; Wang, K. Spatial Grain Effects of Urban Green Space Cover Maps on Assessing Habitat Fragmentation and Connectivity. Land 2021, 10, 1065. https://doi.org/10.3390/land10101065

Academic Editor: Richard

C. Smardon

Received: 9 September 2021

Accepted: 6 October 2021

Published: 9 October 2021

Publisher's Note: MDPI stays neutral with regard to jurisdictional claims in published maps and institutional affiliations.

Copyright: (C) 2021 by the authors. Licensee MDPI, Basel, Switzerland. This article is an open access article distributed under the terms and conditions of the Creative Commons Attribution (CC BY) license (https:/ / creativecommons.org/licenses/by/ $4.0 /)$.

\begin{abstract}
The scientific evaluation of landscape fragmentation and connectivity is important for habitat conservation. It is strongly influenced by the spatial resolution of source maps, particularly in urban environments. However, there is limited comprehensive investigation of the spatial grain effect on urban habitat and few in-depth analysis across different urban gradients. In this paper, we scrutinize the spatial grain effects of urban green space (UGS) cover maps (derived from remote sensing imagery and survey data) with respect to evaluating habitat fragmentation and connectivity, comparing among different urban gradient scenarios (downtown, urban periphery, and suburban area) in Hangzhou, a megacity in China. The fragmentation was detected from three indices, including Entropy, Contagion, and Hypsometry. Then morphological spatial pattern analysis (MSPA) was applied for the landscape element identification. The possibility of connectivity (PC) and patch importance ( $\mathrm{dPC}$ ) were proposed for measuring the landscape connectivity based on Cores and Bridges from MSPA results. The results indicate that the farther the location is from downtown, the less sensitive the landscape element proportion to the spatial resolution. Among the three fragmentation indices, the overall hypsometry index has the lowest sensitivity to the spatial resolution, which implies this index's broader application value. Considering connectivity, high spatial resolution maps are appropriate for analyzing highly heterogeneous urban areas, while medium spatial resolution maps are more applicable to urban periphery and suburban area with larger UGS patches and less fragmentation. This study suggests that the spatial resolution of UGS maps substantially influence habitat fragmentation and connectivity, which is critical for decision making in urban planning and management.
\end{abstract}

Keywords: fragmentation; connectivity; habitat conservation; spatial grain effect; urban green space; morphological spatial pattern analysis

\section{Introduction}

Urban green spaces (UGSs) are important for urban biodiversity maintenance and human well-being [1-4]. However, with continued urbanization and increasing human activities, UGS patches are increasingly fragmented, severely affecting the sustainable development of cities [5]. The loss and fragmentation result in progressive changes in the 
spatial landscape patterns of habitats, affecting species survival and posing serious threat to biodiversity conservation in urban regions [6,7]. Whether in landscape ecology research or urban sustainable development planning, habitat conservation is a topic that has long been valued [4]. In order to ensure that the evaluation of habitat conservation status has higher practical value, it is vital to scientifically measure the landscape patterns [8].

Fragmentation indicates whether a habitat patch is large enough to support population survival of certain species [9]. The key to the evaluation of UGS fragmentation lies in the selection and construction of indicators $[10,11]$. Traditional fragmentation indices, such as mean patch size (MPS) and mean proximity index (MPI) $[6,12,13]$, can be calculated by landscape pattern index software, such as Fragstats [14]. Some studies have adopted a comprehensive multi-index approach to improve fragmentation analysis, such as using principal component analysis to integrate several landscape indices [15].

Connectivity measures the extent to which the landscape facilitates species to move between fragments [16]. Conventional connectivity indices, such as the ecological connectivity index (ECI), monitor the functional connectivity between different elements of the landscape [17]. Mitsova et al. (2011) compared the changes in open space connectivity of urban fringe areas under two scenarios of rapid urbanization and green space protection by using a graph-theory-based software [18], Conefor Sensinode [19,20], involving several connectivity indices such as Harary index $(\mathrm{H})$, landscape coincidence probability (LCP), integral index of connectivity (IIC), and probability of connectivity (PC) [21]. It is worth emphasizing that graph-theoretical approaches measure the importance of corridors between "nodes" in a network but only by using preprocessed data [22]. Therefore an integrative method based on mathematical morphology called morphological spatial pattern analysis (MSPA) was proposed [23]. It classifies the area into mutually exclusive landscape elements such as cores, connectors, edges, and isolated elements [24]. This approach can automatically detect structural links between core patches and provide an analytical basis for effectively constructing urban ecological networks $[25,26]$.

By considering the multi-scale characteristics of the urbanization process, the differences in the response mechanism of the UGS landscape patterns (e.g., the number, area, and spatial structure) can be varied with scale (i.e., grain size and extent) [27-30]. The sensitivity of landscape patterns to spatial resolution has been studied comprehensively in different research directions, for instance, forest conservation, and natural reserve [22]. Ostapowicz et al. (2008) stated that the increase in spatial resolution may result in data generalization resulting in either the removal of the small size features or their potential transformation into non-core MSPA elements. However, the spatial grain effects on urban habitat assessment have received little attention. Coarse spatial resolution data may not reveal spatial heterogeneity of urban landscapes [31,32]. Upscaling of UGS maps can degrade important information, especially some small patches representing the small-scale parks or narrow green belts, which are actually key elements in fine-scale UGS planning and management. Therefore, the exploration of spatial grain effect is vital in fine-scale UGS research.

Spatial grain effect is also associated with landscape composition (e.g., diversity of patch types) and configuration (e.g., spatial arrangement of different patch types) [29]. In effect, landscape patterns can be varied under different urban gradients, which further results in variations in the evaluation results of ecological functions [11,33]. The gradient analysis methods of UGS patterns mainly include the transect analysis method [34], buffer gradient analysis [35], and comparative study based on urban-rural spatial zoning [15,36]. Among them, the method of urban-rural spatial zoning is to divide land use into built-up areas, urban fringe, and rural areas with reference to administrative divisions or government planning standards. The major advantages of this method are simplicity, efficiency, and appropriateness for preliminary comparisons of changes in landscape patterns under different urban-rural gradients [15,36]. Conclusions have been drawn in some studies that the proportion core patches decreased as the spatial resolution increased [9], and differences in composition and configuration did not influence the general tendencies [22], 
which however, are only sound over homogeneous regions such as a forest. The same assessments in the urban context with high spatial heterogeneity could result in different conclusions. As the research perspective gradually extended from a single landscape to landscape gradients, especially across urban and rural landscapes, inference and experience can be obtained to assist urban-rural planning by observing the evaluation results with different input spatial resolutions.

In terms of UGSs, research based on conventional urban landscape metrics can be a daunting task due to the quality and coverage of data sources. Coarse spatial resolution remote data do not accurately detect the sharp edges of irregular patches [37]. This problem raises a range of concerns for accurate monitoring and managing UGSs as a large proportion of vegetation in urban landscape remain complex, irregular, and highly fragmented. Over the years, with the continuous development of remote sensing technologies, the data sources of urban research have been greatly improved in terms of resolution and coverage, which provide practical means for compiling land cover maps [38]. High spatial resolution remotely sensed data (e.g., QuickBird, IKONOS, and GF-2) offer details of UGSs that have enhanced scientific research, planning and management $[39,40]$. Coupled with the updated information extraction methods (e.g., object-based image analysis (OBIA) [41] and deep neural networks [42]), it is no longer a problem to quickly and accurately obtain distribution and change information of UGSs for serving simultaneous observation and ecological environment evolution at different scales. Although a considerable number of studies have utilized coarse, medium and high spatial resolution data to analyze UGSs, it is imperative to scrutinize systematically and comprehensively the degree to which spatial resolution (grain) influences monitoring fragmentation and connectivity of UGSs. Moreover, less attention has been given to how obtained results can benefit research or management objectives of UGSs. Driven by the growing concerns over the impacts of rapid urbanization on UGSs, there is an acute need for the precise detection of fragmentation and connectivity in UGSs.

This paper aims to narrow this gap of information by providing robust knowledge that will enable appropriately using different spatial resolutions data in quantifying fragmentation and connectivity of UGSs. To perform this, we conducted three key steps: (1) extracting UGS maps from source maps with three different spatial resolutions and determining the test extents across urban gradients; (2) quantifying landscape elements by MSPA; and (3) identifying urban habitat fragmentation and connectivity of different scenarios based on index measurements and graph-theoretical approaches.

\section{Materials and Methods}

\subsection{Study Area and Data Preprocess}

Three study areas were selected in the urban districts of Hangzhou City, distributing in the downtown area (in the built-up area), on the urban periphery (the transitional zone on the margin of built-up area), and in the suburban area (outside the built-up area), in order to detect the differences among urban gradients (Figure 1). Hangzhou $\left(118^{\circ} 21^{\prime} \sim 120^{\circ} 30^{\prime} \mathrm{E}, 2^{\circ} 11^{\prime} \sim 30^{\circ} 33^{\prime} \mathrm{N}\right)$, as the capital city of Zhejiang province, China, is located at the southern wing of the Yangtze River Delta. It belongs to the subtropical monsoon climate with four distinct seasons and abundant rainfall. It is also known as a scenic tourist city, famous for the West Lake Scenic Zone and Xixi National Wetland Park. In recent years, the Hangzhou government has conscientiously implemented the spirit of China's construction of ecological civilization [43] in UGS planning and management. It has set clear goals for UGS construction from quantity to quality, from overall planning to details, and is committed to continuously satisfying ecological security and aesthetics of the living environment. In 2017, Hangzhou was officially awarded the title of "National Ecological Garden City" on the Global Cities Forum. As of 2019, the green coverage rate of Hangzhou's built-up area has reached $40.58 \%$, and the total number of scenic spots in the urban districts has reached 260, covering an area of 3208 ha [44]. Although Hangzhou's greening has reached a relatively high level in terms of quantity, the "quality" level needs 
to be further explored through scientific research, that is, the spatial configuration of UGS patches that can function normally to maintain biodiversity. In this study, we set up a $2000 \mathrm{~m}$ fishnet on the layer of Hangzhou urban districts in order to limit the sample window size and selected the samples based on the urban growth boundary derived from nightlight data, referencing Xue et al.'s (2018) work [45].

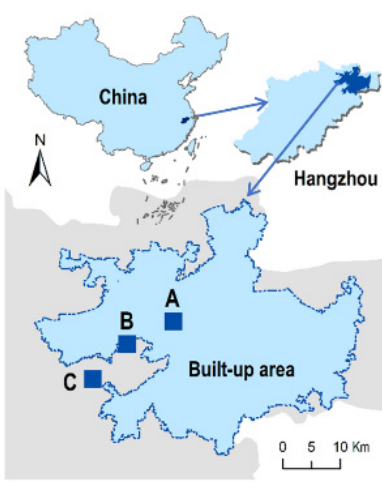

Satellite imagery of the study areas

A

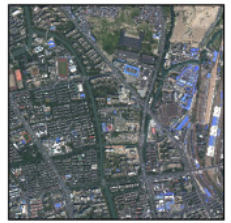

B

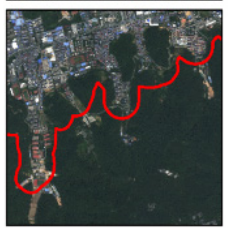

C

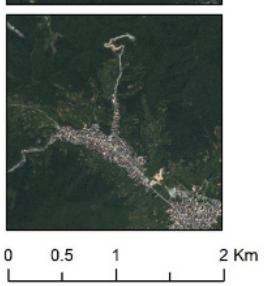

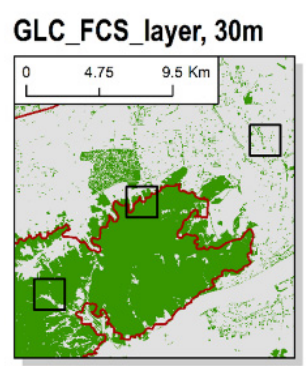

A

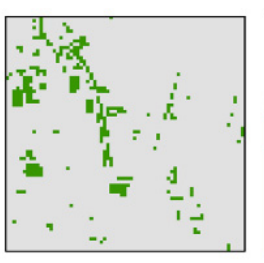

Forest_layer, 10m

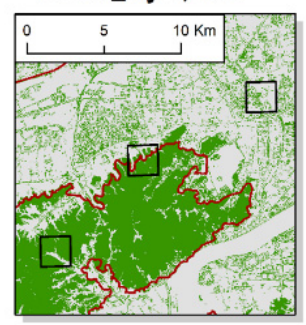

OBIA_layer, $1 \mathrm{~m}$

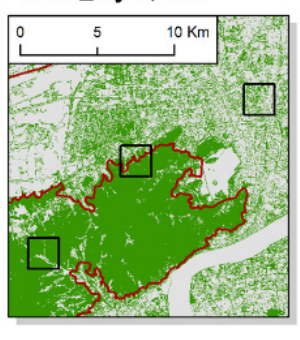

Urban growth boundary
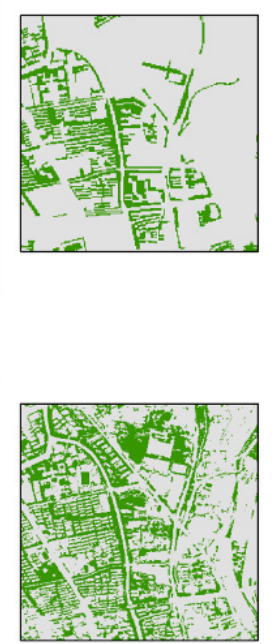

UGS
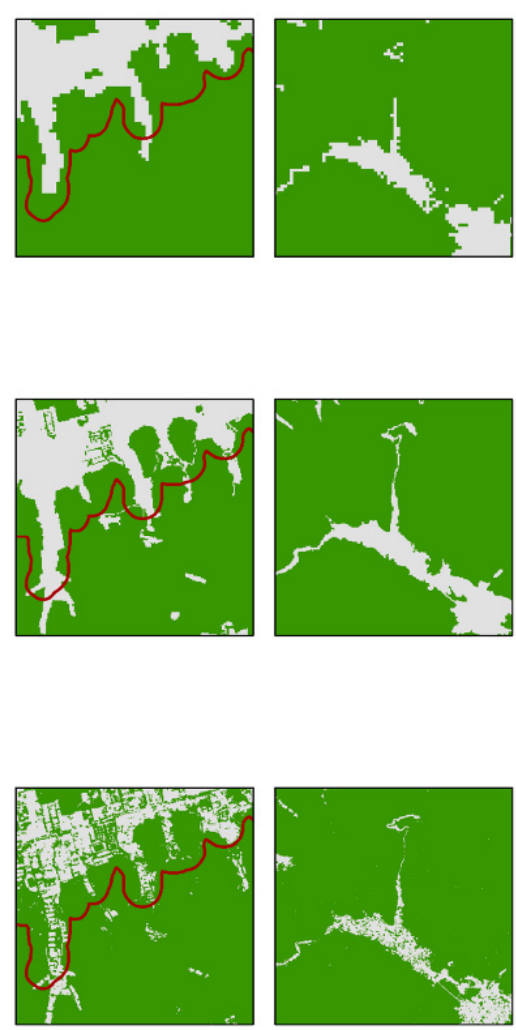

Non-UGS

$0 \quad 0.5$

$2 \mathrm{Km}$

Figure 1. Three UGS maps with different spatial resolutions, i.e., GLC_FCS_layer (30 m), Forest_layer (10 m), and OBIA layer $(1 \mathrm{~m})$. Scenario A, B, and C are the three chosen sample study areas located in the downtown area, on the urban periphery, and in the suburban area.

Three UGS cover maps with different input spatial resolutions were considered in this study:

1. The GCS_FCS_layer (30 $\mathrm{m}$ spatial resolution) was derived from a novel global $30 \mathrm{~m}$ land-cover classification with a fine classification system for the year 2020 (GLC_FCS30-2020) [46]. In order to map the GCS_FCS_layer, we filtered out the corresponding vegetation coverage categories in the source map as UGSs and defined the remaining categories as non-UGSs.

2. The Forest_layer (10 m spatial resolution) was derived from the Forest Resource Inventory in Zhejiang province [47]. Forest resource planning and design investigation were organized and carried out by the county-level state-owned forestry bureau and forest farm. The vegetation patch survey within the entire survey area was mainly adopted, covering urban and rural areas. In 2017, the Zhejiang Forestry Department deployed and carried out a forest resource inventory update, including the inventory of forest community structure, naturalness, and other vegetation (e.g., herbaceous 
plants) and ecological factors, taking two years to complete. This work has laid the foundation for the establishment of the provincial forestry ecological monitoring system and ecological construction. In this study, the forestry survey patches are regard as UGS patches, and the remaining space are regarded as non-UGS patches.

3. The OBIA_layer (1 m spatial resolution) was derived from the GF-2 remote sensing imagery in 2019 (China Centre For Resources Satellite Data and Application, http: / / www.cresda.com/EN/, accessed on 10 December 2020) in order to obtain more detailed UGS cover maps than the previous maps, fitting better to the actual margin of UGSs. Preprocessing (geometric correction and image sharpening) of remote sensing imagery was completed on ENVI 5.3®. The OBIA technique, consisting of segmentation and classification, was derived using eCognition $\AA$. For the segmentation phase, the ESP2 tool [48] was applied to obtain the optimal segmentation scale as 76 for the multi-scale segmentation; the support vector machine (SVM) was selected as the classifier for the classification phase based on the selection of a series of spectral features including mean value and standard deviation of blue/green/red, brightness, and NDVI. Finally, the OBIA_layer was obtained with two classes including UGS and non-UGS.

\subsection{Fragmentation}

In this study, we selected three indices, Entropy, Contagion, and Hypsometry, to reveal fragmentation. The three indices were all measured in GuidosToolbox software, version 3.0 [49]. The input image in GuidosToolbox is required to be a binary raster map with foreground/background, where the foreground corresponds to the class of interest (e.g., UGS patches), and the background (non-UGS patches) is its complement. We computed three fragmentation indices for the nine raster samples. These three indices are able to join all rasters within the sample area and derive a global value, making the results comparable and aiding trend analysis. Triple information was intended to be explored in this section: (1) the trends of fragmentation degrees with gradient, (2) the sensitivity of different input data sources to these trends, and (3) the sensitivity of different fragmentation indices to different data sources.

\subsubsection{Entropy}

In thermodynamics, Entropy indicates the degree of disorder in a system, whereas the concept could be transferred as an indicator for spatial fragmentation in spatial geometry [50]. For a given foreground, an image with a single foreground object has minimum entropy; when the given area is split into a maximum number and dispersed equally over the entire image, Entropy reaches the maximum value [51]. This study achieved Entropy according to the algorithm, which could be traced from the classical definition of entropy in information theory [52]. In Shannon's original concept, $P_{i}$ refers to percentages of species classes in categorical maps [50]. Here, for the binary raster maps, the algorithm area is applied to investigate the differences between cell values in all 8 directions, and log is the base 2 logarithm [49]. The FRAG entropy is defined as follows.

$$
F R A G_{\text {entropy }}=-\sum P_{i} * \log _{2}\left(P_{i}\right)
$$

\subsubsection{Contagion}

The traditional contagion index (CONTAG) describes the degree of agglomeration or spreading trend of different patch types in the landscape. Generally speaking, a high sprawl value (tends to $100 \%$ ) indicates that a certain dominant patch type in the landscape has formed good connectivity; on the contrary (tends to 0), it indicates that the landscape is a dense pattern with multiple elements, where the degree of fragmentation is relatively high $[50,53]$. Therefore, the fragmentation index here can be defined as the reciprocal relation of the contagion index, i.e., an image region with high contagion is equivalent to having low fragmentation. The $F R A G_{\text {Contagion }}$ is defined as follows: 


$$
\text { CONTAG }=\left\{1+\frac{\sum_{i=1}^{m} \sum_{k=1}^{m}\left[P_{i} \times \frac{g_{i k}}{\sum_{k=1}^{m} g_{i k}} \times \ln \left(P_{i} \times \frac{g_{i k}}{\sum_{k=1}^{m} g_{i k}}\right)\right]}{2 \ln (m)}\right\} \times 100 \% \text { FRAG } G_{\text {contagion }}=1-\text { CONTAG }
$$

where $P_{i}$ is the percentage of the area occupied by type $i$ patches; $g_{i k}$ is the number of adjacent patches of type $i$ and type $k ; \mathrm{m}$ is the total number of patch types. In this study, type $i$ represents the foreground (UGS), type $k$ represents the background (Non-UGS), and the total number of patch types $\mathrm{m}$ is 2 .

\subsubsection{Hypsometry}

Habitat fragmentation can be measured based on the normalized landscape hypsometric curve (NLHC), which was derived by [54]. NLHC summarizes the Euclidean distance distribution for a given binary landscape map as positive values in the foreground and negative values in the background. The degree of fragmentation corresponds to the area under the NLHC covered between minimum possible fragmentations and maximum fragmentation [54]. Hypsometry provides values in the range of $[0,100] \%$. The degree of an overall fragmentation for a given image is defined by the weighted sum of fragmentation in the foreground and the background:

$F R A G_{\text {hypsometry }}=\left(\frac{f g_{-} \text {area }}{f g_{-} \text {frag }}+\frac{b g_{-} \text {area }}{b g_{-} \text {frag }}\right) \times 100 \% f_{g_{-}}$frag $=\int_{0}^{1} N L H C_{f g}-\int_{0}^{1} N L H C_{f g_{-} \text {min }} b g_{-} f r a g=\int_{-1}^{0} N L H C_{b g}-\int_{-1}^{0} N L H C_{b g_{-} \text {min }}$

where $b g / f g_{-}$area is the foreground/background area, respectively, and $b g / f g_{-} f r a g$ is the foreground/background fragmentation, respectively. $N L H C_{f g / b g}$ is an NLHC for the foreground /background class of a given landscape, and $N L H C_{f g / b g_{-} \min }$ is an NLHC for the foreground/background class of a landscape with the same proportion of foreground but maximum foreground aggregation (i.e., minimum fragmentation).

\subsection{Landscape Elements Identification}

We applied MSPA to detect the landscape elements of the UGS patches, which is also performed with GuidosToolbox 3.0. MSPA is a customized sequence of mathematical morphological operators, targeted at the description of the geometry and connectivity of the image components [24]. The foreground area can be classified as seven generic MSPA elements at the pixel level: Core, Islet, Bridge, Loop, Edge, Perforation, and Branch, which are mutually exclusive (Figure 2). The meaning of MSPA elements is explained in Table 1.
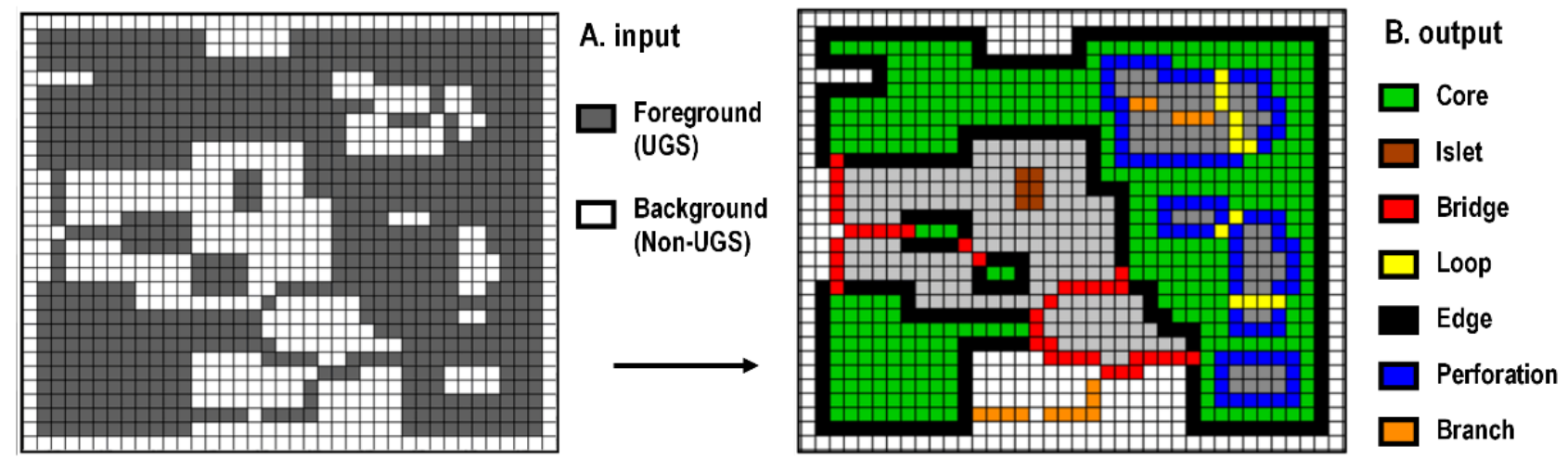

Figure 2. An example of seven morphological spatial pattern MSPA elements. Example illustrating MSPA analysis: (A) input binary map where the foreground corresponds to UGS and background to non-UGS; (B) output of MSPA analysis. This figure was depicted based on the following source: http://forest.jrc.ec.europa.eu/download/software/guidos/mspa/ (accessed on 12 May 2021). 
Table 1. Descriptions of the seven MSPA element types under mathematical and landscape ecological meaning.

\begin{tabular}{|c|c|c|}
\hline Landscape Element Type & Spatial Morphological Definition * & Landscape Ecological Meaning \\
\hline Core & Interior area excluding perimeter & $\begin{array}{l}\text { Larger habitat patches in foreground pixels, providing } \\
\text { relatively larger habitats space for species; represents } \\
\text { ecological sources of importance for protecting biodiversity }\end{array}$ \\
\hline Islet & Disjoint and too small to contain Core & $\begin{array}{l}\text { Isolated, broken small patches that are not connected to } \\
\text { each other, with low connectivity }\end{array}$ \\
\hline Bridge & Connected to different Core area & $\begin{array}{l}\text { Narrow area connected the cores, representing a corridor } \\
\text { that connects patches in an ecological network; essential for } \\
\text { biological migration and landscape connectivity }\end{array}$ \\
\hline Loop & Connected to the same Core area & $\begin{array}{l}\text { Similar to the Bridge, but only represents the corridors that } \\
\text { communicate within the same core for the migration of } \\
\text { internal species }\end{array}$ \\
\hline Edge & External object parameter & $\begin{array}{l}\text { Transitional zone between the core zone and the external } \\
\text { non-green space; its width varies according to the migration } \\
\text { characteristics of different species }\end{array}$ \\
\hline Perforation & Internal object parameter & $\begin{array}{l}\text { Transitional zone between the core zone and the internal } \\
\text { non-green space; its width varies according to the migration } \\
\text { characteristics of different species }\end{array}$ \\
\hline Branch & $\begin{array}{l}\text { Connected at one end to Edge, } \\
\text { perforation, Bridge, or Loop }\end{array}$ & $\begin{array}{l}\text { Extending area of green space; only one end is connected to } \\
\text { the green space }\end{array}$ \\
\hline
\end{tabular}

* Source: http://forest.jrc.ec.europa.eu/download/software/guidos/mspa/ (accessed on 12 May 2021).

GuidosToolbox has introduced two key parameters that influence the sensitivity of MSPA results to the input scale: pixel size $\mathrm{P}$ and parameter $\mathrm{S}$ for determining the edge width [22]. In general, $P$ depends on the input spatial resolution of the binary maps. The increase in P may result in the decrease in detailed elements (e.g., Islet, Loop, Bridge, and Branch). The customized S directly determines the width threshold of the Edge, Perforation, Loop, and Bridge, which are set according to the theoretical basis of the landscape ecological design [55]. In this study, P was the study object and already set based on the three input UGS maps. The setting of $S$ is based on the following considerations.

For many species, edge effect is one of the main factors affecting habitat quality. The edge effect is mainly caused by changes in the microclimate effects (such as edge light, wind, dryness, etc.), resulting in changes in the composition of edge vegetation and the depth for edge species to enter the habitat [55]. However, with the change of vegetation types and target species, the influence range of the edge effect varies greatly, ranging from a meter to a hundred meters. In specific planning, consideration should be given to actual conditions. Since there is currently no clear agreement on the appropriate edge width for urban habitat patches, we can only summarize it through extensive literature review. Previous studies have argued that when the width of the biological protection corridor is set to $30 \mathrm{~m}$, the river ecosystem can be protected from logging [56], fish, reptiles, amphibians, birds and mammals can be protected [6,57], and the minimum corridor width for shade-tolerant tree species can be maintained [58]. Moreover, from the experimental level, because the green patches inside the city is much smaller and fragmentized, setting the edge width too large will cause the research to fail to detect the core area, thus affecting the results. Therefore, the edge width has been recommended to be $30 \mathrm{~m}$ for the scenarios in this study.

\subsection{Connectivity}

In this study, connectivity index analysis was conducted with Conefor Sensinode software, version 2.6 [20], available for the outputs obtained in the MSPA analysis. We applied the probability of connectivity (PC) index, defined as the probability that a species falls into surrounding reachable habitat patches [19]. Only the core and bridge are considered in the connectivity index analysis [59]. According to the extent of the study areas, the distribution of UGS patches, and existing research references, the distance threshold was determined to 
be $1000 \mathrm{~m}$, and the probability was $0.5[19,26,60]$. The equation of PC index is shown as follows:

$$
\mathrm{PC}=\frac{\sum_{i=1}^{n} \sum_{j=1}^{n} a_{i} a_{j} P_{i j}^{*}}{A_{L}^{2}}
$$

where $n$ is the total number of patches in the landscape, $P_{i j}^{*}$ represents the maximum probability of species spreading between patch $i$ and patch $j, a_{i}$ and $a_{j}$ represent the areas of patch $i$ and $j$, respectively, and $A_{L}$ is the area of the landscape.

The patch importance (dPC) was also calculated. The patch importance is presented as the delta of PC, and it allows the identification and prioritization of important patches that mostly contribute to overall landscape connectivity [59]. The higher the APC, the higher the importance of the patch in landscape connectivity and the more obvious its core status in the UGS landscape system. The equation is shown as follows:

$$
\mathrm{dPC}(\%)=\frac{P C-P C^{\prime}}{P C} \times 100 \%
$$

where PC indicates the possible connectivity index of a patch in the landscape, and $P C^{\prime}$ indicates the possible connectivity index of the landscape after the patch is removed.

\section{Results}

\subsection{Fragmentation}

Entropy, Contagion, and Hypsometry were computed for the fragmentation based on different spatial resolutions in three urban gradient scenarios (Figure 3). In terms of the Entropy index, OBIA_layer had the lowest fragmentation value. With increasing distance from downtown areas (from scenario A to C), the Entropy of the three maps gradually declines, and the trend of Forest_layer is the most significant. With respect to Contagion, OBIA_layer had the lowest fragmentation value. From scenario A to C, the Contagion of the three maps dropped, and thereafter behaved steady. Focusing on Hypsometry, from scenario A to C, the Hypsometry of the three maps generally declined. In each scenario, the overall hypsometry index showed similar values in the three maps.

(a) Entropy

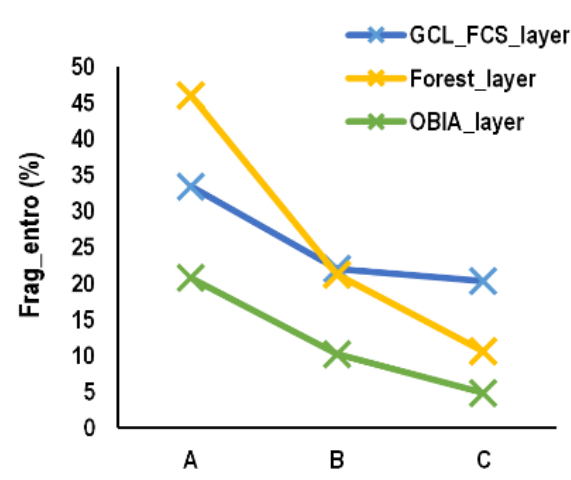

(b) Contagion

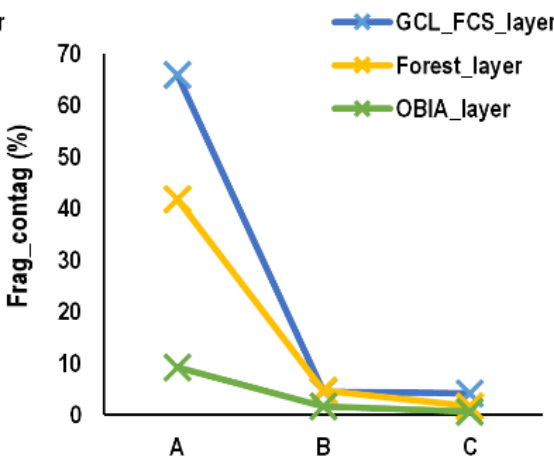

(c) Hypsometry

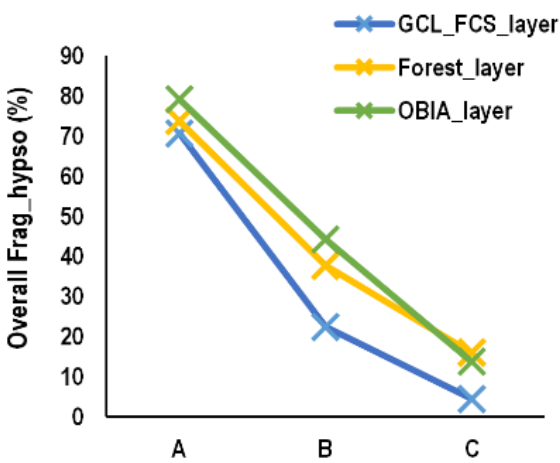

Figure 3. Describing the fragmentation level of maps with different spatial resolutions in different urban scenarios from the three indices: (a) Entropy, (b) Contagion, and (c) Hypsometry.

The normalized landscape hypsometric curve (NLHC) provided detailed information for understanding internal mechanisms (Figure 4). The shape of the NLHC depicted a spatial structure of a given landscape. For a given landscape, the degree of fragmentation corresponded to the area under the NLHC covered between minimum possible fragmentation (black) and maximum fragmentation (red). The degree of fragmentation in the foreground and background decreased with increasing distance from the downtown area. This finding implied that NLHC can more stably reflect the relationship between the proportion of patch coverage and the degree of fragmentation. Among different input 
spatial resolutions, foreground fragmentation did not provide a clear trend. However, the background fragmentation showed a clear trend for it had a neutralizing effect on the overall index.

A
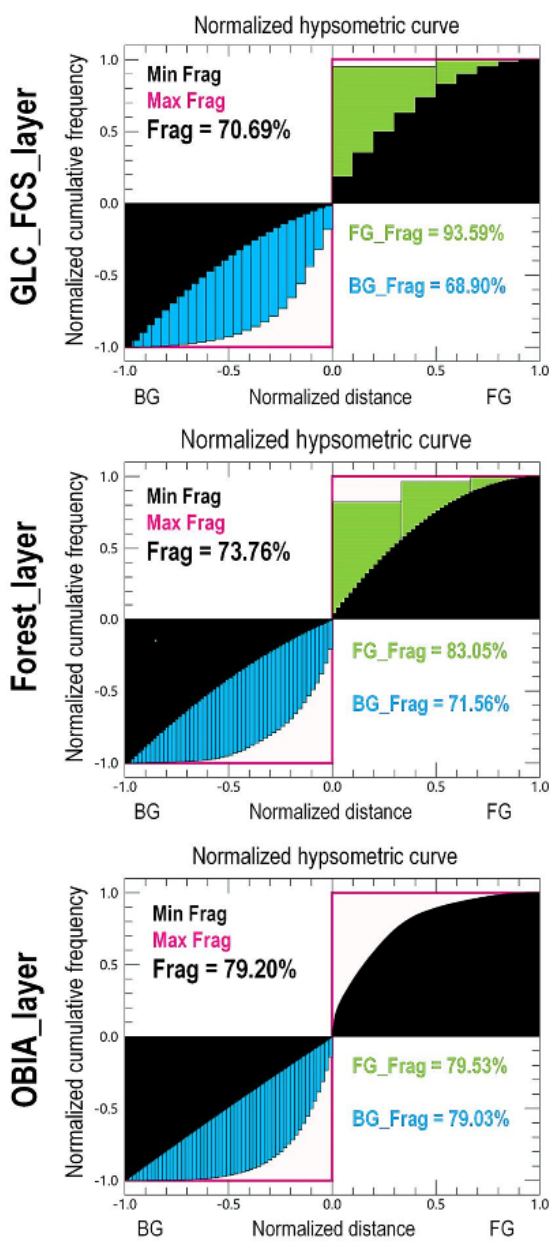

B

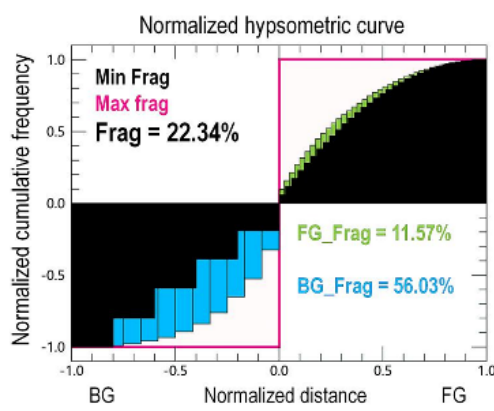

Normalized hypsometric curve

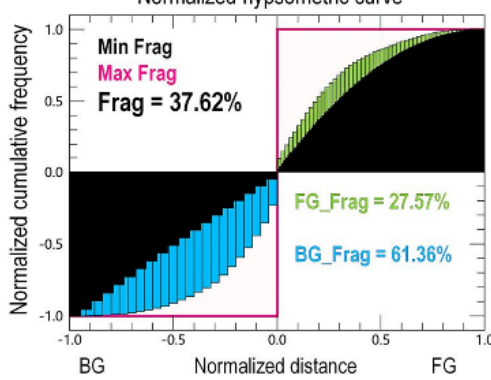

Normalized hypsometric curve

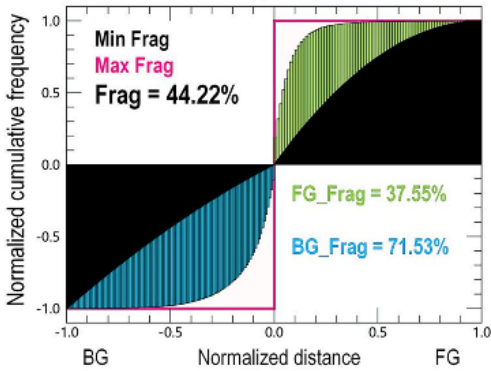

C
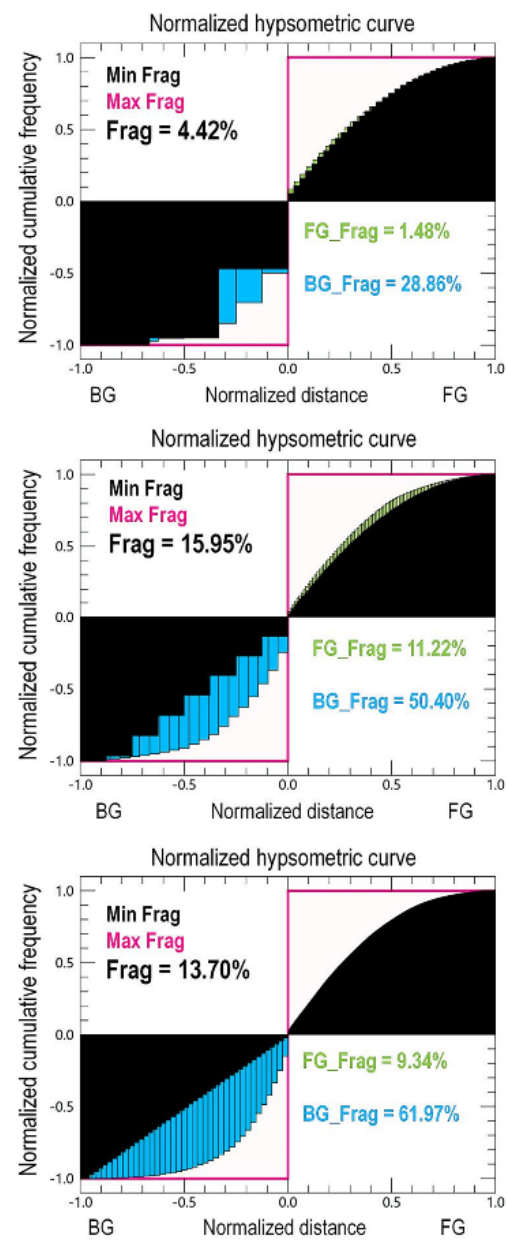

Figure 4. NLHCs calculated for study areas with different UGS cover maps across urban gradients. The distributions of urban gradient scenario A, B, and C are in Figure 1. The overall fragmentation index is shown at the top left corner in each chart, while fragmentation of its foreground (i.e., forest) component is shown in green, and its background component (i.e., non-forest) is in blue. The degree of fragmentation corresponds to the area under the NLHC covered between minimum possible fragmentation (black) and maximum fragmentation (red).

\subsection{Landscape Elements Identification}

Based on MSPA, the three urban gradient scenarios (A, B, and C) of the three maps all form pixel maps composed of seven landscape elements (Figure 5). We also counted the proportion and number of elements in each sample (Table 2) in order to observe the sensitivity of the MSPA results to the input spatial resolution.

In the terms of controlling the extent variable (400 ha sample window), the farther location in the same map is from the downtown area, the higher the foreground proportion (UGS), and this phenomenon exists in all three maps. However, the proportion variations of the same urban gradient scenario in different maps were not parallel. Specifically, as the spatial resolution increased, the foreground proportion of scenario A (downtown) gradually increased, while scenario $B$ (on the urban periphery) and scenario $C$ (suburban area) both decreased first and thereafter increased. The OBIA_layer in all three scenarios had the highest foreground proportion. The standard deviation gradually decreased from 
downtown area to suburban area, indicating that the foreground proportion is similar among maps with different input spatial resolutions.

Among the seven landscape elements, the Cores and the Bridge deserved special attention. Observing the nine scenarios, scenario C of GLC_FCS_layer had the largest area of Core (327.48 ha, $81.87 \%$ in total) while scenario A of OBIA_layer had the largest area of Bridge ( 36.20 ha, $9.05 \%$ in total). In the same map, the farther the location is from the downtown area, the higher the Core proportion, and this phenomenon exists in all three maps; the bridge area does not show obvious laws related to the urban gradient. However, in the same scenario, the Core proportion was not significantly sensitive to the spatial resolution whereas the Bridge showed a significant positive correlation with the spatial resolution. Meanwhile, the standard deviation of the proportion gradually decreased from scenario A to scenario $\mathrm{C}$, indicating that the Bridge proportion tended to be similar among maps with different input spatial resolutions.
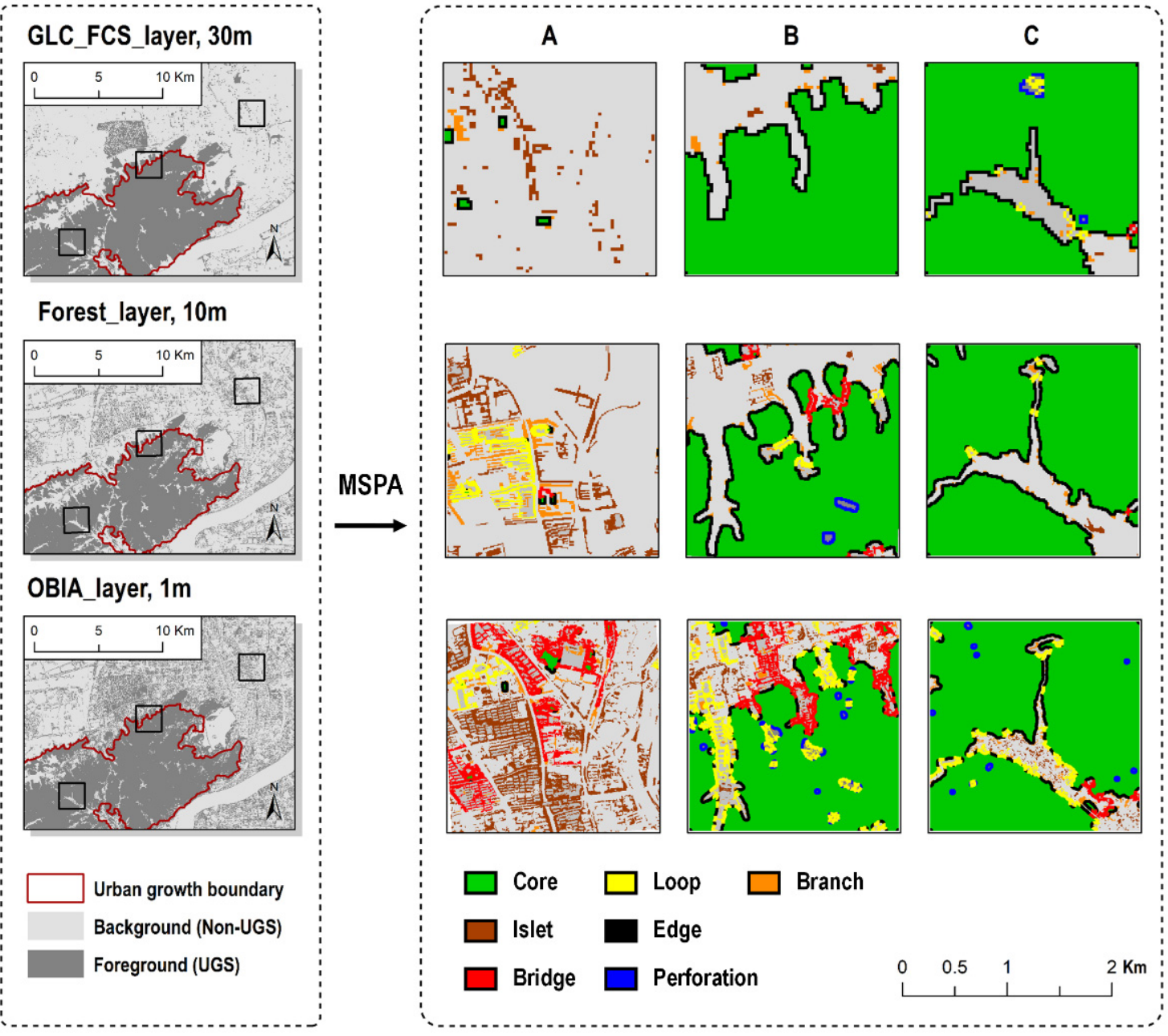

Figure 5. MSPA results of the three maps (GLC_GCS_layer, Forest_layer, and OBIA_layer) in the three scenarios (A, B, and C) with seven landscape elements. The distributions of A, B, and C are in Figure 1.

\subsection{Connectivity}

The PC index results for each UGS cover map are shown from the overall PC index value, dPC, and area (Table 3). The two key landscape elements, i.e., Core and Bridge, were counted separately for they have different connotations and functions in landscape ecology and urban practice (Table 3). Distributions of the value range of Cores and Bridges are also displayed (Figure 6). 


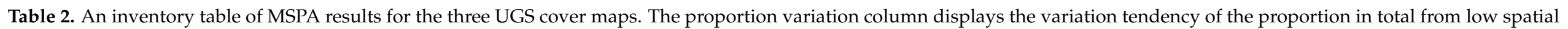
resolution map to high-resolution map.

\begin{tabular}{|c|c|c|c|c|c|c|c|c|c|c|c|c|c|c|c|c|c|}
\hline \multirow[b]{2}{*}{$\begin{array}{c}\text { MSPA } \\
\text { Elements }\end{array}$} & \multirow[b]{2}{*}{$\begin{array}{l}\text { Urban } \\
\text { Gradient } \\
\text { Scenario }\end{array}$} & \multicolumn{4}{|c|}{ 1. GCL_FCS_layer $(30 \mathrm{~m})$} & \multicolumn{4}{|c|}{ 2. Forest_layer $(10 \mathrm{~m})$} & \multicolumn{4}{|c|}{ 3. OBIA_layer (1 m) } & \multicolumn{4}{|c|}{ Proportion Variation } \\
\hline & & $\begin{array}{c}\text { Proportion } \\
\text { in Fore- } \\
\text { ground } \\
(\%)\end{array}$ & $\begin{array}{l}\text { Proportion } \\
\text { in Total } \\
(\%)\end{array}$ & $\begin{array}{c}\text { Area } \\
\text { (ha) }\end{array}$ & $\begin{array}{c}\text { Element } \\
\text { Num- } \\
\text { ber }\end{array}$ & $\begin{array}{c}\text { Proportion } \\
\text { in Fore- } \\
\text { ground } \\
(\%)\end{array}$ & $\begin{array}{c}\text { Proportion } \\
\text { in Total } \\
(\%)\end{array}$ & $\begin{array}{c}\text { Area } \\
\text { (ha) }\end{array}$ & $\begin{array}{c}\text { Element } \\
\text { Num- } \\
\text { ber }\end{array}$ & $\begin{array}{c}\text { Proportion } \\
\text { in Fore- } \\
\text { ground } \\
(\%)\end{array}$ & $\begin{array}{l}\text { Proportion } \\
\text { in Total } \\
(\%)\end{array}$ & $\begin{array}{c}\text { Area } \\
\text { (ha) }\end{array}$ & $\begin{array}{l}\text { Element } \\
\text { Num- } \\
\text { ber }\end{array}$ & $1 \rightarrow 2$ & $2 \rightarrow 3$ & $1 \rightarrow 3$ & Stdev \\
\hline \multirow[t]{2}{*}{ Foreground } & B & - & 75.77 & 303.08 & - & - & 70.27 & 281.08 & - & - & 80.36 & 321.44 & - & & 7 & $y$ & $\begin{array}{l}10.00 \\
5.05\end{array}$ \\
\hline & $\mathrm{C}$ & - & 89.27 & 357.08 & - & - & 87.93 & 351.72 & - & - & 92.16 & 368.64 & - & & & $\nearrow$ & 2.16 \\
\hline \multirow[b]{2}{*}{ Core } & A & 4.83 & 0.35 & 1.4 & 4 & 0.28 & 0.05 & 0.21 & 5 & 1.35 & 0.47 & 1.88 & 15 & & $\nearrow$ & $\nearrow$ & 0.22 \\
\hline & B & 90.24 & 68.37 & 273.48 & 3 & 78.91 & 55.45 & 221.80 & 6 & 68.59 & 55.12 & 220.48 & 12 & & & & 7.56 \\
\hline \multirow{3}{*}{ Islet } & $\mathrm{A}$ & 71.30 & 5.18 & 20.72 & 48 & 49.32 & 9.45 & 37.8 & 61 & 55.15 & 19.06 & 76.24 & 607 & & $\nearrow$ & $\nearrow$ & 7.11 \\
\hline & B & 0.55 & 0.42 & 1.68 & 2 & 1.33 & 0.94 & 3.76 & 30 & 2.55 & 2.05 & 8.20 & 156 & & & 7 & 0.83 \\
\hline & $\mathrm{C}$ & 0.07 & 0.07 & 0.28 & 1 & 0.27 & 0.24 & 0.96 & 2 & 0.85 & 0.79 & 3.16 & 156 & & & $y$ & 0.38 \\
\hline \multirow{3}{*}{ Bridge } & $\mathrm{A}$ & 0.00 & 0.00 & 0.00 & 0 & 0.74 & 0.14 & 0.56 & 1 & 26.19 & 9.05 & 36.20 & 66 & & $\nearrow$ & $\nearrow$ & 5.19 \\
\hline & B & 0.00 & 0.00 & 0.00 & 0 & 0.97 & 0.68 & 2.72 & 14 & 5.74 & 4.61 & 18.44 & 149 & & & 7 & 2.49 \\
\hline & C & 0.00 & 0.00 & 0.00 & 0 & 0.00 & 0.00 & 0.00 & 0 & 0.44 & 0.41 & 1.64 & 36 & $\rightarrow$ & & 7 & 0.24 \\
\hline \multirow{3}{*}{ Loop } & $\mathrm{A}$ & 0.00 & 0.00 & 0.00 & 0 & 24.62 & 4.72 & 18.88 & 5 & 5.11 & 1.77 & 7.08 & 13 & & & $\nearrow$ & 2.38 \\
\hline & B & 0.00 & 0.00 & 0.00 & 0 & 0.35 & 0.25 & 1.00 & 3 & 4.79 & 3.85 & 15.40 & 280 & & & $\nearrow$ & 2.15 \\
\hline & $\mathrm{C}$ & 0.54 & 0.48 & 1.92 & 6 & 0.09 & 0.08 & 0.32 & 4 & 0.96 & 0.88 & 3.52 & 163 & & & $\nearrow$ & 0.40 \\
\hline Edge & $\mathrm{C}$ & 6.15 & 5.49 & 21.96 & 5 & 8.24 & 7.24 & 28.96 & 7 & 8.17 & 7.53 & 30.12 & 10 & & & $\nearrow$ & 1.10 \\
\hline \multirow{3}{*}{ Perforation } & A & 0.00 & 0.00 & 0.00 & 0 & 0.00 & 0.00 & 0.00 & 0 & 0.00 & 0.00 & 0.00 & 0 & $\rightarrow$ & $\rightarrow$ & $\rightarrow$ & 0.00 \\
\hline & B & 0.00 & 0.00 & 0.00 & 0 & 0.99 & 0.70 & 2.80 & 2 & 4.01 & 3.22 & 12.88 & 13 & & & $\nearrow$ & 1.69 \\
\hline & C & 0.89 & 0.79 & 3.16 & 2 & 0.00 & 0.00 & 0.00 & 0 & 1.07 & 0.99 & 3.96 & 10 & & & $x$ & 0.52 \\
\hline \multirow{3}{*}{ Branch } & $\mathrm{A}$ & 10.27 & 0.75 & 3.00 & 6 & 20.64 & 3.96 & 15.84 & 77 & 5.68 & 1.96 & 7.84 & 221 & & & $\nearrow$ & 1.62 \\
\hline & B & 1.13 & 0.86 & 3.44 & 18 & 1.76 & 1.24 & 4.96 & 89 & 1.93 & 1.55 & 6.20 & 538 & & & $x$ & 0.35 \\
\hline & C & 0.64 & 0.57 & 2.28 & 18 & 0.65 & 0.57 & 0.28 & 51 & 1.01 & 0.94 & 3.76 & 435 & & & 7 & 0.21 \\
\hline \multirow{3}{*}{ Background } & $\mathrm{A}$ & - & 92.73 & 370.92 & - & - & 80.83 & 323.32 & - & - & 65.45 & 261.8 & - & & & $\searrow$ & 13.68 \\
\hline & B & - & 24.23 & 96.92 & - & - & 29.73 & 118.92 & - & - & 19.64 & 78.56 & - & & & 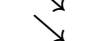 & 5.05 \\
\hline & C & - & 10.73 & 42.92 & - & - & 12.07 & 48.28 & - & - & 7.84 & 31.36 & - & & 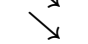 & $\searrow$ & 2.16 \\
\hline
\end{tabular}

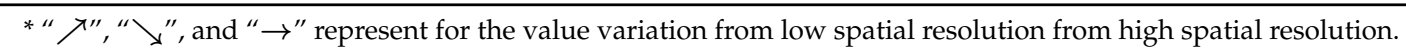


Table 3. PC index results for each UGS cover map: PC value, the top three dPC of Cores and Bridges, and the total area ( (area) of all obtained Cores and Bridges.

\begin{tabular}{|c|c|c|c|c|c|c|c|c|c|c|}
\hline & \multicolumn{3}{|c|}{ GCL_FCS_layer $(30 \mathrm{~m})$} & \multicolumn{3}{|c|}{ Forest_layer $(10 \mathrm{~m})$} & \multicolumn{3}{|c|}{ OBIA_layer (1 m) } \\
\hline & & A & B & $\mathrm{C}$ & A & B & C & A & B & $\mathrm{C}$ \\
\hline \multirow[t]{2}{*}{$\begin{array}{l}\mathrm{PC} \\
\mathrm{dPC}(\%)\end{array}$} & & 0.0000093 & 30.49 & 0.71 & 0.0000086 & 60.37 & 0.70 & 0.011 & 0.39 & 0.67 \\
\hline & First & 59.57 & 99.98 & 99.99 & 13.19 & 97.66 & 92.62 & 6.07 & 94.66 & 99.98 \\
\hline \multirow{2}{*}{ Core } & Second & 51.84 & 2.07 & 0.37 & 9.98 & 17.27 & 44.98 & 0.71 & 15.35 & 0.10 \\
\hline & Third & 27.39 & 0.11 & - & 4.71 & 3.32 & 0.47 & 0.40 & 3.07 & 0.05 \\
\hline \multirow{5}{*}{ Bridge } & $\begin{array}{c}\text { Marea } \\
\text { (ha) }\end{array}$ & 1.44 & 280.35 & 335.70 & 0.23 & 235.52 & 339.03 & 1.87 & 220.68 & 322.84 \\
\hline & First & - & - & 0.16 & 76.62 & 1.42 & 0.20 & 41.62 & 6.77 & 0.64 \\
\hline & Second & - & - & 0.16 & 30.00 & 0.88 & - & 32.81 & 2.27 & 0.44 \\
\hline & Third & - & - & 0.05 & 28.52 & 0.50 & - & 24.48 & 2.15 & 0.32 \\
\hline & $\underset{\text { (ha) }}{\text { Marea }}$ & - & - & 0.72 & 0.97 & 9.06 & 0.32 & 42.90 & 31.94 & 4.23 \\
\hline \multicolumn{2}{|c|}{ Earea (ha) } & 1.44 & 280.35 & 335.70 & 1.20 & 235.58 & 339.35 & 44.77 & 252.62 & 327.07 \\
\hline
\end{tabular}
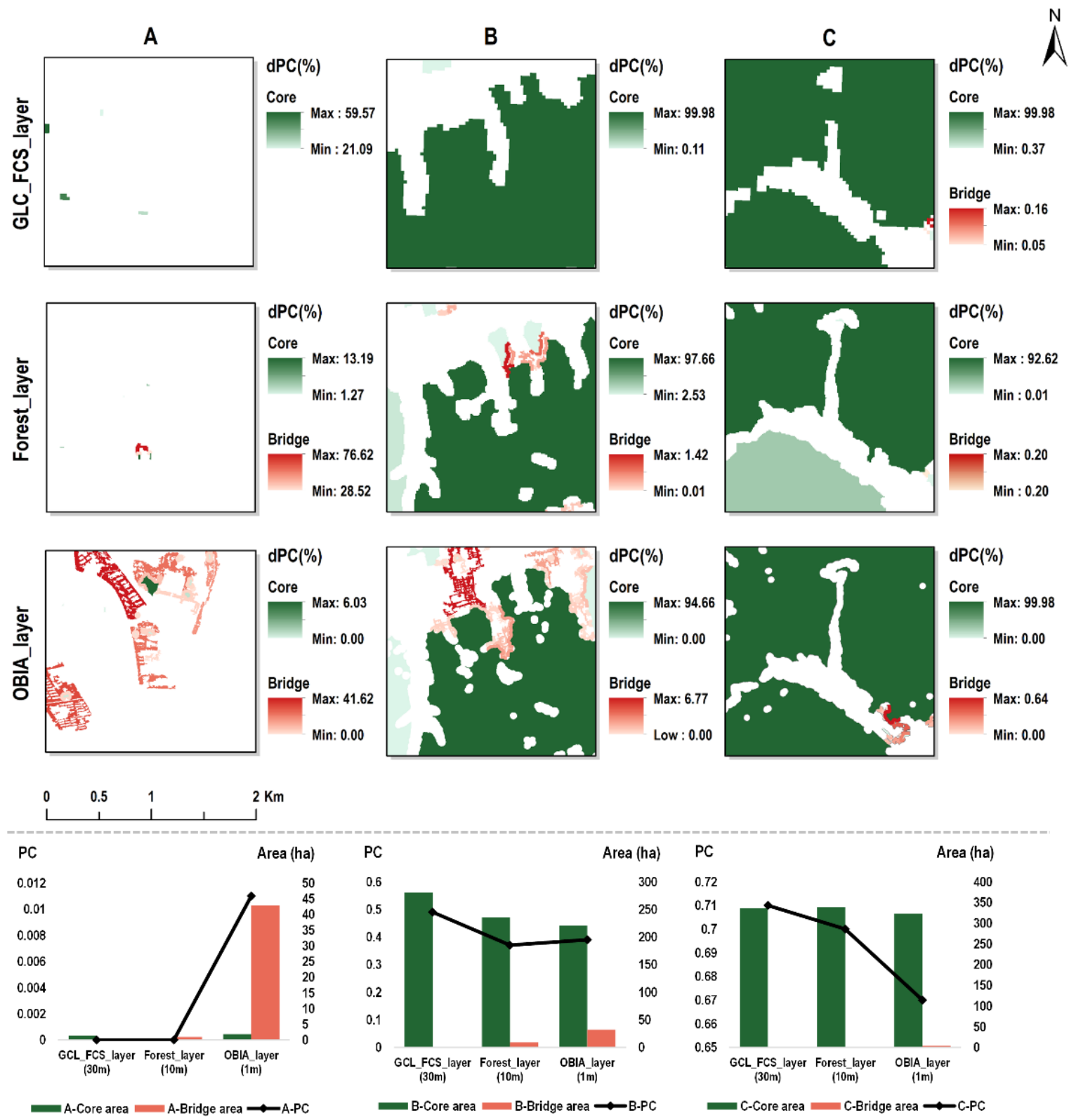

Figure 6. Distribution of the top important three Cores and Bridges in the urban gradient scenarios of the three maps. The distributions of urban gradient scenario A, B, and C are in Figure 1. The bottom charts show the PC value and Core/Bridge area of different maps in the corresponding study area. 
In each map, PC gradually increased from scenario A to C. For a single scenario, OBIA_layer in A had the highest possible connectivity ( $\mathrm{PC}=0.011)$, and GCL_FCS_layer in $\mathrm{B}$ and $\mathrm{C}$ was the highest $(\mathrm{PC}=0.49,0.71)$. In scenario $\mathrm{A}$ and $\mathrm{B}$, the $\mathrm{dPC}$ of the first important Cores decreased as the spatial resolution increases; in scenario $\mathrm{C}, \mathrm{dPC}$ first decreased and then increased.

Given bridge blocks changed very slightly in the GCL_FCS_layer, so we only focused on Forest_layer and OBIA_layer. In scenario A, the importance of the first important patch of Forest_layer was higher than that of OBIA_layer. In fact, Forest_layer had very few Bridges identified and did not represent a better description of the connectivity of Forest_layer in scenario A; on the contrary, the description on OBIA_layer's Bridges was more accurate. The area of the OBIA_layer bridge area and the dPC of the first important patch indicated both the highest values in scenarios B and C.

\section{Discussion}

\subsection{The Spatial Grain Effect on Urban Habitat Landscape Patterns}

As the most intuitive aspect of characterizing the habitat quality, fragmentation was the primary index that we considered in this study. Although the patterns of the calculation results of the three fragmentation indices were different, they all showed a general trend: from downtown area to the urban periphery, the fragmentation of UGS patches gradually decreased. This is easy to understand: The UGS patches in urban area are small and fragmented, while urban periphery mostly consisted of contiguous forests. On the other hand, the sensitivity of the three indices relative to different spatial resolutions was significantly different because of their own mechanisms behind them. This implies that if the data source is limited, which index can be the recommended one for evaluating the fragmentation of urban habitats.

Specifically, both Entropy and Contagion can be regarded as local aggregation metrics but with a crucial difference: Contagion only considers foreground objects, while Entropy is based on the simultaneous evaluation of foreground and background [49]. For instance, a map with $90 \%$ of background coverage and a $10 \%$ of isolated foreground objects may result in high fragmentation values for Contagion. However, for Entropy, this map will have low fragmentation values because the dominant area coverage (background) is only slightly fragmented by the foreground; low fragmentation value can still be obtained for Entropy if the percentage of foreground and background is inverted. In this study, taking GCL_FCS_layer as an example, the range of fragmentation value for Entropy in the three scenarios is not very extensive and remains at a low level (Figure 3a), indicating that the results well verified the above mechanism, while the fragmentation value for Contagion is particularly high in scenario A (Figure $3 b$ ). In short, Entropy is suitable for input data with similar proportions of foreground and background and cannot reflect the difference between different urban gradients significantly when the proportion of foreground and background is far apart; the calculation on Contagion only considers the foreground, which is not applicable in the case where the proportion of foreground and background is relatively large. Compared with the former two indices, Hypsometry has better stability and is minimally affected by the input spatial resolution (Figure 3c). The mechanism for NLHC was found that, for foreground coverage below $50 \%$, there was a positively correlated relationship between foreground coverage and the NLHC-based fragmentation index and vice versa [54]. We believe that the Hypsometry index combines duality and normalization to neutralize and generalize the fragmentation value, so that the fragmentation values of layers of different spatial resolutions are similar, which includes so-called lower sensitivity and higher stability. Therefore, we argue that if the data source is limited in the fineness of spatial resolution, the overall hypsometry index is a considerable choice for evaluating habitat landscape. Although this study shows that the Hypsometry index is more stable towards changing spatial resolution, as long as the basic conditions and planning requirements of the different study areas are clarified, these three indices can be properly applied according to the situation. 
This research provided detailed information due to exploring the changes in the MSPA element proportion across urban gradient scenarios rather than analyzing single spatial resolution over a study region $[31,61]$. Standard deviation was employed to describe the MSPA elements proportion fluctuation in each spatial resolution. The foreground and most MSPA landscape elements showed a significant downward trend with increasing distance from the downtown area. This pattern indicated that the farther from the downtown area, the less sensitive the MSPA element proportion is relative to spatial resolution. For example, the layers of different spatial resolutions showed little difference in the landscape element proportion in a contiguous forest at urban periphery; in terms of the downtown area, there existed obvious differences because high spatial resolution layers are more robust for capturing fine information. This finding suggests two potential directions: (1) Higher landscape heterogeneity may result in the selection of high spatial resolution input layers; (2) if the study area has a significant urban landscape gradient, multi-scale layers can be adopted in lieu of single spatial resolution.

Connectivity indices indicates the ecological endowment of habitat patches and provide scientific guidance for the construction of ecological networks in the future. Although the above-mentioned conclusions tended to choose higher spatial resolution maps, they may not be fully applicable in the analysis of connectivity. First, in a large number of contiguous forests around the city, Perforation may increase as the spatial resolution increases, so PC may decrease as the spatial resolution increases, which may result in an overestimation towards certain planning and management scale. Then, the performance of OBIA_layer's on dPCs of the Bridges is more accurate, which play a more important role than Cores, especially in scenario A; with the GLC_FCS_layer, the opposite result was obtained, and Cores were not so small and were more important for connectivity, especially in scenario $C$. The observed finding implies that if planners or researchers are constructing ecological networks based on connectivity analysis, the study of the urban area should pay more attention to the expression of details on the map. Thus, fine spatial resolution maps are an appropriate choice. If the study area is focused on the urban periphery, with high habitat coverage and low fragmentation, then the medium spatial resolution is a better choice, which can avoid overestimation and improve computing efficiency.

In general, the UGS landscape patterns of different countries are also quite different. For example, if maps with $30 \mathrm{~m}$ resolution is are used for monitoring the "pocket parks" in China $[62,63]$, the results could differ greatly from the actual situation, as some parks may not big enough to be identified according to the given grain size; however, such resolution could be sufficient for analysis in some European cities for large and contiguous UGS patches [64]. It is worth noting that in the MSPA results, the Bridge, essential for biological migration and landscape connectivity, is absent in the lower spatial resolution layer, GLC_FCS_layer, but exists in higher spatial resolution layers, Forest_layer and OBIA_layer; the Core, representing ecological sources of importance for protecting biodiversity, was identified in all maps. This means that Core and Bridge are necessarily discussed separately, because they differ in the connotation of landscape functions when describing connectivity, and their sensitivities to spatial resolution are also different. Integrated descriptions can easily neutralize many details.

\subsection{Insights of Data Sources and Methods in Urban Practice}

The selection of the optimal spatial resolution depends upon the research or management objectives and the environmental configuration [65]. In the face of a highly heterogeneous urban environment, refined planning policies and management are essential. In general, the spatial resolutions may be larger than many of the UGS patches under the urban context [66]. Smaller patches of urban vegetation are often misclassified and underestimated because of mixed pixels from remote sensing products derived from low and medium spatial resolution data [67]. However, previous works may be limited by a series of subjective or objective reasons that choose input maps with improper spatial resolutions to evaluate urban habitat conservation status: (1) neglecting the analysis of the 
spatial grain effect of input UGS cover maps only to obtain results quickly and roughly; and (2) the limitations of the access to data source acquirement resulting in low spatial resolution.

Remote sensing data enable systematic mapping of landscape patterns of UGSs over a range of spatial scales, including local, regional and global scales [68]. While medium spatial resolution images such as Landsat data are very useful for monitoring broader patterns of vegetation fragmentation in urban areas, they may fail to capture fine-grained change patterns [69]. A number of studies demonstrated significant difference in quantitative information of landscape pattern indices derived from medium spatial resolution images in comparison with those from high spatial resolution data [70,71]. Just as the results in this study, the evaluation based on the OBIA_layer is the most accurate. The foreground proportion and the number of elements of Forest_layer and GLC_FCS_layer are both less than those of OBIA_layer, and this phenomenon is most prominent in the downtown area. Compared to the OBIA_layer, the spatial resolution of the remote sensing data deriving GLC_FCS_layer is low, and the classification accuracy is not high; the Forest_layer is precise enough, but it takes time and resources to conduct field work in the early stage, and the main objects are woody plants. On the contrary, the OBIA_layer is derived from high spatial resolution remote sensing images, which is closer to the real ground cover and can be compiled in the office. The main disadvantages of this layer are as follows: knowledge of the image processing software, being large and cumbersome to store, manipulate and process, and high costs [72]. Therefore, data fusion and merging of medium and high remote sensing data could be cost effective in mapping large cities and urban areas [73].

Additionally, a research or management project should take into account the efficiency and feasibility of the methods. The MSPA is a highly efficient method that provides accurate landscape spatial configurations. MSPA is not only useful for forestry applications but this technique can also be applied to other fields [22,74], such as urban green infrastructure [9,32,61], water networks [23], and farmland [75]. This study takes advantage of MSPA and focuses on UGSs, where the scale issue may be magnified under urban context for its particular heterogeneity and numerous small patches.

\subsection{Limitations and Future Prospects}

Considering the limitation of data acquisition, this study only discussed three spatial resolution. Future studies should apply more maps extracted from remote sensing data (e.g., GF-1(2 m), SPOT $5(2.5 \mathrm{~m} / 5 \mathrm{~m})$, etc.) in order to obtain finer spatial resolution intervals, which can be more convincing for the exploration of laws. In addition, since this study only considered the spatial grain effect and controlled the scale variable of "extent", multi-scaled research based on the direction of "extent" can also be carried out in the future. For example, landscape variations can be detected from a metropolitan scale to the city scale. Furthermore, this article mainly described the spatial scale, and future research can introduce the time dimension in order to explore the differences in the results of dynamic changes in landscape patterns due to the variation in resolution.

\section{Conclusions}

The spatial resolution of UGS cover maps influences the assessment of urban habitat conservation status. Such differences are critical for decision making in UGS planning and management. Therefore, this study systematically and comprehensively examined the spatial grain effects of UGS cover maps with different spatial resolutions for measuring urban habitat fragmentation and connectivity, comparing the landscape patterns in different urban gradient scenarios. By combining the MSPA and a series of landscape indices, key conclusions can be conducted: (1) The farther the downtown area, the lower the sensitivity of landscape element proportion relative to spatial resolution; (2) among the three fragmentation indices, the overall hypsometry index is less sensitive to spatial resolution, which can be recommended as an alternative index for evaluating the fragmentation of urban habitats if the high spatial resolution imagery is limited; (3) when assessing connectivity, 
high spatial resolution maps are suitable for focusing on highly heterogeneous urban areas, and medium spatial resolution is more suitable for focusing on urban periphery with large habitat patches and low fragmentation.

Revelations have been excavated from this study that the spatial grain effect is quite different among urban gradients. Different index selection will also result in different habitat assessment results. Compared to a simple calculation of an overall index, the combination of high spatial resolution UGS cover maps and MSPA is much more workable for analysis. In addition, remote sensing techniques and OBIA can provide cost-effective approach for supporting high spatial resolution data source input. The results based on this layer are more accurate, reproducible, and consistent, allowing comparisons over time. Our findings demonstrate that UGS practice should strike a balance between objectives and selecting appropriate spatial resolution to obtain reliable outcomes.

Author Contributions: Conceptualization, Y.L. and M.G.; methodology, Y.L. and A.S.; software, Y.L.; validation, Y.L.; formal analysis, Y.L.; investigation, Y.L. and M.G.; resources, M.G. and K.W.; data curation, Y.L.; writing-original draft preparation, Y.L.; writing-review and editing, Y.L., Z.Y., L.H. (Lingyan Huang), C.Z. and M.G.; visualization, Y.L.; supervision, K.W. and M.G.; project administration, W.A., L.H. (Lu Huang), K.W. and M.G.; funding acquisition, J.Z., M.G. and K.W. All authors have read and agreed to the published version of the manuscript.

Funding: This research was supported by the Fundamental Research Funds for the Central Universities (Grant No. 2021QN81014), the Open Fund of Key Laboratory of Urban Land Resources Monitoring and Simulation, Ministry of Natural Resources (Grant No. KF-2020-05-073), and the Project Supported by the Open Fund of Technology Innovation Center for Land Spatial Eco-restoration a Metropolitan Area, Ministry of Natural Resources (Grant No. CXZX202010).

Data Availability Statement: The data presented in this study are available upon request from the corresponding author.

Acknowledgments: We acknowledge the valuable comments and suggestions of all the anonymous referees and editors of Land.

Conflicts of Interest: The authors declare no conflict of interest.

\section{References}

1. Mao, Q.; Huang, G.; Wu, J. Urban Ecosystem Services: A Review. Chin. J. Appl. Ecol. 2015, 26, 1023-1033.

2. Benedict, M.A.; McMahon, E.T. Green Infrastructure. Urban Environ. Educ. Rev. 2002, 1-18. [CrossRef]

3. Mao, Q.; Luo, S.; Ma, K.; Wu, J.; Tang, R.; Zhang, Y.; Bao, L.; Zhang, T. Research Advances in Ecological Assessment of Urban Greenspace. Acta Ecol. Sin. 2012, 32, 5589-5600.

4. Nassauer, J.I. Landscape Planning and Conservation Biology: Systems Thinking Revisited. Conserv. Biol. 2006, 20, 677-678. [CrossRef] [PubMed]

5. Zhao, J.; Chen, S.; Jiang, B.; Ren, Y.; Wang, H.; Vause, J.; Yu, H. Temporal Trend of Green Space Coverage in China and Its Relationship with Urbanization over the Last Two Decades. Sci. Total Environ. 2013, 442, 455-465. [CrossRef] [PubMed]

6. Forman, R.T.T. Land Mosaics. The Ecology of Landscapes and Regions; Camebridge University Press: Cambridge, UK, 1995; ISBN 978-0-521-47462-7.

7. Liu, Y.; Feng, Y.; Zhao, Z.; Zhang, Q.; Su, S. Socioeconomic Drivers of Forest Loss and Fragmentation: A Comparison between Different Land Use Planning Schemes and Policy Implications. Land Use Policy 2016, 54, 58-68. [CrossRef]

8. Leitão, A.B.; Ahern, J. Applying Landscape Ecological Concepts and Metrics in Sustainable Landscape Planning. Landsc. Urban Plan. 2002, 59, 65-93. [CrossRef]

9. Hernando, A.; Velázquez, J.; Valbuena, R.; Legrand, M.; García-Abril, A. Influence of the Resolution of Forest Cover Maps in Evaluating Fragmentation and Connectivity to Assess Habitat Conservation Status. Ecol. Indic. 2017, 79, 295-302. [CrossRef]

10. Jiao, M.; Hu, M.; Xia, B. Spatiotemporal Dynamic Simulation of Land-Use and Landscape-Pattern in the Pearl River Delta, China. Sustain. Cities Soc. 2019, 49, 101581. [CrossRef]

11. Tao, Y.; Li, F.; Wang, R.; Zhao, D. Research Progress in the Quantitative Methods of Urban Green Space Patterns. Acta Ecol. Sin. 2013, 33, 2330-2342. [CrossRef]

12. Crossman, N.D.; Bryan, B.A.; Ostendorf, B.; Collins, S. Systematic Landscape Restoration in the Rural-Urban Fringe: Meeting Conservation Planning and Policy Goals. Biodivers. Conserv. 2007, 16, 3781-3802. [CrossRef]

13. Rutledge, D. Landscape Indices as Measures of the Effects of Fragmentation: Can Pattern Reflect Process? New Zealand Department of Conservation: Wellington, New Zealand, 2003; ISBN 0478223803. 
14. McGarigal, K.; Cushman, S.; Ene, E. FRAGSTATS v4: Spatial Pattern Analysis Program for Categorical and Continuous Maps. 2012. Available online: https:/ / www.umass.edu/landeco/research/fragstats/fragstats.html (accessed on 7 October 2021).

15. Tian, Y.; Jim, C.Y.; Tao, Y.; Shi, T. Landscape Ecological Assessment of Green Space Fragmentation in Hong Kong. Urban For. Urban Green. 2011, 10, 79-86. [CrossRef]

16. Vogt, P.; Ferrari, J.R.; Lookingbill, T.R.; Gardner, R.H.; Riitters, K.H.; Ostapowicz, K. Mapping Functional Connectivity. Ecol. Indic. 2009, 9, 64-71. [CrossRef]

17. Marulli, J.; Mallarach, J. A GIS Methodology for Assessing Ecological Connectivity: Application to the Barcelona Metropolitan Area. Landsc. Urban Plan. 2005, 71, 243-262. [CrossRef]

18. Mitsova, D.; Shuster, W.; Wang, X. A Cellular Automata Model of Land Cover Change to Integrate Urban Growth with Open Space Conservation. Landsc. Urban Plan. 2011, 99, 141-153. [CrossRef]

19. Saura, S.; Pascual-Hortal, L. A New Habitat Availability Index to Integrate Connectivity in Landscape Conservation Planning: Comparison with Existing Indices and Application to a Case Study. Landsc. Urban Plan. 2007, 83, 91-103. [CrossRef]

20. Saura, S.; Torné, J. Conefor Sensinode 2.2: A Software Package for Quantifying the Importance of Habitat Patches for Landscape Connectivity. Environ. Model. Softw. 2009, 24, 135-139. [CrossRef]

21. Pascual-Hortal, L.; Saura, S. Comparison and Development of New Graph-Based Landscape Connectivity Indices: Towards the Priorization of Habitat Patches and Corridors for Conservation. Landsc. Ecol. 2006, 21, 959-967. [CrossRef]

22. Ostapowicz, K.; Vogt, P.; Riitters, K.H.; Kozak, J.; Estreguil, C. Impact of Scale on Morphological Spatial Pattern of Forest. Landsc. Ecol. 2008, 23, 1107-1117. [CrossRef]

23. Soille, P. Morphological Image Analysis: Principles and Application; Springer: New York, NY, USA, 2003.

24. Soille, P.; Vogt, P. Morphological Segmentation of Binary Patterns. Pattern Recognit. Lett. 2009, 30, 456-459. [CrossRef]

25. Xu, F.; Yin, H.; Kong, F.; Xu, J. Developing Ecological Networks Based on Mspa and the Least-Cost Path Method: A Case Study in Bazhong Western New District. Acta Ecol. Sin. 2015, 35, 6425-6434.

26. Chen, J.; Zuo, X.; Peng, J.S.; Ou, Z.; Sun, Z. Construction of Urban Ecological Networks Based on MSPA and Landscape Connectivity Analysisw A Case Study in Longyang District. J. West China For. Sci. 2020, 49, 118-123.

27. Wiens, J.A. Spatial Scaling in Ecology. Funct. Ecol. 1989, 3, 385. [CrossRef]

28. Wu, J. Hierarchy and Scaling: Extrapolating Information along a Scaling Ladder. Can. J. Remote Sens. 1999, 25, 367-380. [CrossRef]

29. Wu, J.; Shen, W.; Sun, W.; Tueller, P.T. Empirical Patterns of the Effects of Changing Scale on Landscape Metrics. Landsc. Ecol. 2002, 17, 761-782. [CrossRef]

30. Cushman, S.A.; Littell, J.; McGarigal, K. The Problem of Ecological Scaling in Spatially Complex, Nonequilibrium Ecological Systems; Cushman, S.A., Huettmann, F., Eds.; Spatial Complexity, Informatics, and Wildlife Conservation; Springer: Tokyo, Janpan, 2010; ISBN 978-4-431-87771-4.

31. Yu, Y.; Yin, H.; Kong, F.; Wang, J.; Xu, W. Scale Effect of Nanjing Urban Green Infrastructure Network Pattern and Connectivity Analysis. Chin. J. Appl. Ecol. 2016, 27, 2119-2127.

32. Chang, Q.; Liu, X.; Wu, J.; He, P. MSPA-Based Urban Green Infrastructure Planning and Management Approach for Urban Sustainability: Case Study of Longgang in China. J. Urban Plan. Dev. 2015, 141, 1-15. [CrossRef]

33. Kong, F.; Nakagoshi, N. Spatial-Temporal Gradient Analysis of Urban Green Spaces in Jinan, China. Landsc. Urban Plan. 2006, 78, 147-164. [CrossRef]

34. Uy, P.D.; Nakagoshi, N. Analyzing Urban Green Space Pattern and Eco-Network in Hanoi, Vietnam. Landsc. Ecol. Eng. 2007, 3, 143-157. [CrossRef]

35. Sun, J.; Xia, H.; Lan, C.; Xin, K. A Gradient Analysis Based on the Buffer Zones of Urban Landscape Pattern of the Constructed Area in Guigang City, Guangxi, China. Acta Ecol. Sin. 2006, 26, 655-662. [CrossRef]

36. Warren, P.S.; Ryan, R.L.; Lerman, S.B.; Tooke, K.A. Social and Institutional Factors Associated with Land Use and Forest Conservation along Two Urban Gradients in Massachusetts. Landsc. Urban Plan. 2011, 102, 82-92. [CrossRef]

37. Karl, J.W.; Maurer, B.A. Multivariate Correlations between Imagery and Field Measurements across Scales: Comparing Pixel Aggregation and Image Segmentation. Landsc. Ecol. 2010, 25, 591-605. [CrossRef]

38. Shao, G.; Wu, J. On the Accuracy of Landscape Pattern Analysis Using Remote Sensing Data. Landsc. Ecol. 2008, $23,505-511$. [CrossRef]

39. Bruzzone, L.; Carlin, L. A Multilevel Context-Based System for Classification of Very High Spatial Resolution Images. IEEE Trans. Geosci. Remote Sens. 2006, 44, 2587-2600. [CrossRef]

40. Tuia, D.; Ratle, F.; Pacifici, F.; Kanevski, M.F.; Emery, W.J. Active Learning Methods for Remote Sensing Image Classification; IEEE: New York, NY, USA, 2009; Volume 47, ISBN 1000121135.

41. Blaschke, T. Object Based Image Analysis for Remote Sensing. ISPRS J. Photogramm. Remote Sens. 2010, 65, 2-16. [CrossRef]

42. Zhao, W.; Du, S.; Emery, W.J. Object-Based Convolutional Neural Network for High-Resolution Imagery Classification. IEEE J. Sel. Top. Appl. Earth Obs. Remote Sens. 2017, 10, 3386-3396. [CrossRef]

43. CPC. Report to the 18th National Congress of the CPC; CPC: Seattle, WA, USA, 2012.

44. Bureau of Hangzhou Statistics. Hangzhou Statistical Yearbook; Bureau of Hangzhou Statistics: Hangzhou, China, 2020.

45. Xue, X.; Yu, Z.; Zhu, S.; Zheng, Q.; Weston, M.; Wang, K.; Gan, M.; Xu, H. Delineating Urban Boundaries Using Landsat 8 Multispectral Data and VIIRS Nighttime Light Data. Remote Sens. 2018, 10, 799. [CrossRef] 
46. Liu, L.; Zhang, X.; Chen, X.; Gao, Y.; Mi, J. GLC_FCS30-2020: Global Land Cover with Fine Classification System at 30m in 2020. Earth Syst. Sci. Data. 2020, 13, 2753-2776.

47. Zhejiang Forestry Bureau Report on the Progress of the Forest Resource Inventory in Zhejiang Province. Available online: http://www.zjly.gov.cn/art/2017/2/22/art_1276365_5788187.html. (accessed on 9 October 2020).

48. Drăguț, L.; Csillik, O.; Eisank, C.; Tiede, D. Automated Parameterisation for Multi-Scale Image Segmentation on Multiple Layers. ISPRS J. Photogramm. Remote Sens. 2014, 88, 119-127. [CrossRef]

49. Vogt, P.; Riitters, K. GuidosToolbox: Universal Digital Image Object Analysis. Eur. J. Remote Sens. 2017, 50, 352-361. [CrossRef]

50. Vogt, P. User Guide of GuidosToolbox; European Commission Joint Research Centre: Ispra, Italy, 2020.

51. Wang, D.; Fang, S.; Yang, Z.; Wang, L.; Tang, W.; Li, Y.; Tong, C. A Regional Mapping Method for Oilseed Rape Based on HSV Transformation and Spectral Features. ISPRS Int. J. Geo-Inf. 2018, 7, 224. [CrossRef]

52. Shannon, C.E. A Mathematical Theory of Communication. Bell Syst. Tech. J. 1948, 27, 379-423. [CrossRef]

53. He, H.S.; DeZonia, B.E.; Mladenoff, D.J. An Aggregation Index (AI) to Quantify Spatial Patterns of Landscapes. Landsc. Ecol. 2000, 15, 591-601. [CrossRef]

54. Kozak, J.; Ziółkowska, E.; Vogt, P.; Dobosz, M.; Kaim, D.; Kolecka, N.; Ostafin, K. Forest-Cover Increase Does Not Trigger Forest-Fragmentation Decrease: Case Study from the Polish Carpathians. Sustain. Switz. 2018, 10, 1472. [CrossRef]

55. Zhu, Q.; Yu, K.J.; Li, D.H. The Width of Ecological Corridor in Landscape Planning. Acta Ecol. Sin. 2005, 25, 2406-2412. [CrossRef]

56. Budd, W.W.; Cohen, P.L.; Saunders, P.R.; Steiner, F.R. Stream Corridor Management in the Pacific Northwest: I. Determination of Stream-Corridor Widths. Environ. Manage. 1987, 11, 587-597. [CrossRef]

57. Large, A.R.G.; Petts, G.E. Rehabilitation of River Margins; Blackwell Science: Hoboken, NJ, USA, 1994.

58. Peterjohn, W.T.; Correll, D.L. Nutrient Dynamics in an Agricultural Watershed: Observations on the Role of A Riparian Forest. Ecology 1984, 65, 1466-1475. [CrossRef]

59. Saura, S.; Vogt, P.; Velázquez, J.; Hernando, A.; Tejera, R. Key Structural Forest Connectors Can Be Identified by Combining Landscape Spatial Pattern and Network Analyses. For. Ecol. Manag. 2011, 262, 150-160. [CrossRef]

60. Shi, H.; Xu, Y. Research on Planning Method of Urban Green Space Core Region Based on Landscape Connectivity. J. Nanjing For. Univ. 2011, 35, 51-56.

61. Wickham, J.D.; Riitters, K.H.; Wade, T.G.; Vogt, P. A National Assessment of Green Infrastructure and Change for the Conterminous United States Using Morphological Image Processing. Landsc. Urban Plan. 2010, 94, 186-195. [CrossRef]

62. Liu, H.; Remme, R.P.; Hamel, P.; Nong, H.; Ren, H. Supply and Demand Assessment of Urban Recreation Service and Its Implication for Greenspace Planning-A Case Study on Guangzhou. Landsc. Urban Plan. 2020, 203, 103898. [CrossRef]

63. Zhang, H.; Han, M. Pocket Parks in English and Chinese Literature: A Review. Urban For. Urban Green. 2021, 61, 127080. [CrossRef]

64. Zepp, H.; Groß, L.; Inostroza, L. And the Winner Is? Comparing Urban Green Space Provision and Accessibility in Eight European Metropolitan Areas Using a Spatially Explicit Approach. Urban For. Urban Green. 2020, 49, 126603. [CrossRef]

65. Lam, N.S.N.; Quattrochi, D. On the Issues of Scale, Resolution, and Fractal Analysis in the Mapping Sciences. Prof. Geogr. 1992, 44, 88-98. [CrossRef]

66. Moilanen, A.; Hanski, I. Metapopulation Dynamics: Effects of Habitat Quality and Landscape Structure. Ecology 1998, 79, 2503-2515. [CrossRef]

67. Boyle, S.A.; Kennedy, C.M.; Torres, J.; Colman, K.; Pérez-Estigarribia, P.E.; De La Sancha, N.U. High-Resolution Satellite Imagery Is an Important yet Underutilized Resource in Conservation Biology. PLoS ONE 2014, 9, e86908. [CrossRef]

68. Schneider, A.; Woodcock, C.E. Compact, Dispersed, Fragmented, Extensive? A Comparison of Urban Growth in Twenty-Five Global Cities Using Remotely Sensed Data, Pattern Metrics and Census Information. Urban Stud. 2008, 45, 659-692. [CrossRef]

69. Qian, Y.; Zhou, W.; Yu, W.; Pickett, S.T.A. Quantifying Spatiotemporal Pattern of Urban Greenspace: New Insights from High Resolution Data. Landsc. Ecol. 2015, 30, 1165-1173. [CrossRef]

70. Buyantuyev, A.; Wu, J.; Gries, C. Multiscale Analysis of the Urbanization Pattern of the Phoenix Metropolitan Landscape of USA: Time, Space and Thematic Resolution. Landsc. Urban Plan. 2010, 94, 206-217. [CrossRef]

71. Shen, W.; Jenerette, G.D.; Wu, J.; Gardner, R.H. Evaluating Empirical Scaling Relations of Pattern Metrics with Simulated Landscapes. Ecography 2004, 27, 459-469. [CrossRef]

72. Gillespie, T.W.; Foody, G.M.; Rocchini, D.; Giorgi, A.P.; Saatchi, S. Measuring and Modelling Biodiversity from Space. Prog. Phys. Geogr. 2008, 32, 203-221. [CrossRef]

73. Chen, G.; Hay, G.J.; St-Onge, B. A GEOBIA Framework to Estimate Forest Parameters from Lidar Transects, Quickbird Imagery and Machine Learning: A Case Study in Quebec, Canada. Int. J. Appl. Earth Obs. Geoinf. 2012, 15, 28-37. [CrossRef]

74. Riitters, K.H.; Vogt, P.; Soille, P.; Kozak, J.; Estreguil, C. Neutral Model Analysis of Landscape Patterns from Mathematical Morphology. Landsc. Ecol. 2007, 22, 1033-1043. [CrossRef]

75. Cheng, L.; Xia, N.; Jiang, P.; Zhong, L.; Pian, Y.; Duan, Y.; Huang, Q.; Li, M. Analysis of Farmland Fragmentation in China Modernization Demonstration Zone since "Reform and Openness": A Case Study of South Jiangsu Province. Sci. Rep. 2015, 5, 1-11. [CrossRef] 